\title{
Regional variations in transport of the luminal contents of the rat epididymis in vivo
}

\author{
Ulla-Marjut Jaakkola
}

\begin{abstract}
Laboratory of Animal Physiology, Department of Biology, University of Turku, 20500 Turku 50, Finland
\end{abstract}

\begin{abstract}
Summary. The speed of transport of the luminal contents of the epididymis was studied by injecting small droplets of stained paraffin oil into the lumen in 10 different regions of the epididymal duct of 64 anaesthetized rats and measuring the distances the droplets moved in $2 \mathrm{~h}$. The oil droplets became dispersed, and there was much variation between the animals. The dispersion distances were longest in the proximal caput and shortest in the corpus. The distributions of the transport distances of the oil droplets were discontinuous and multimodal in the proximal caput, and bimodal in the cauda. The transport speed decreased steeply from $420 \mathrm{~mm} / 2 \mathrm{~h}$ in the most proximal caput to $64.2 \mathrm{~mm} / 2 \mathrm{~h}$ in the beginning of the distal caput. In the rest of the caput, corpus and cauda, speed was quite similar although it declined slightly towards the ductus deferens, being $25.5 \mathrm{~mm} / 2 \mathrm{~h}$ in the most distal region of the cauda.
\end{abstract}

\section{Introduction}

Spermatozoa acquire their fertilizing ability during passage through the epididymis, in different parts of the caput and/or corpus, depending on the species (Bedford, 1966; Orgebin-Crist, 1967). During transport the fluid in which the spermatozoa are suspended changes in its ionic and macromolecular composition (Crabo \& Hunter, 1975; Orgebin-Crist, Danzo \& Davies, 1975). Maturation of spermatozoa is assumed to be related to the time of exposure to the luminal fluids of different composition during epididymal passages. The rate of fluid transport from the testis is constant (Setchell, 1978), and effective fluid uptake takes place in the ductuli efferentes and proximal ductus epididymidis (Crabo, 1965), thus presumably reducing fluid flow from the testis to the ductus deferens through the epididymis.

Contractions of the smooth muscle lining the epididymal duct appear to provide the propelling force for epididymal contents. The frequency and extent of propagation of the contractions change throughout the duct (Talo, Jaakkola \& Markkula-Viitanen, 1979). Although the transit time of spermatozoa through the major segments of the epididymis has been measured in several mammals (for review see Courot, 1981), there are no quantitative data on the transport speed in any species.

In the present study the transport speeds of the luminal contents were measured in different areas of the rat epididymis.

\section{Materials and Methods}

Male Sprague-Dawley rats $(\mathrm{N}=64)$ were anaesthetized with ether. The testes and epididymides were exposed through a low midline abdominal incision and a small incision about $1 \mathrm{~mm}$ long was made in the epididymal capsule of the selected region. Droplets of paraffin oil, intensely stained 
with Sudan Black, were injected through a bevelled microcapillary (Hinton \& Setchell, 1978) into the lumen of the epididymal duct in 10 different regions of the epididymis, 6 in the caput, 1 in the middle corpus and 3 in the cauda (Text-fig. 1). Oil droplets were injected into one of the designated regions; in 15 animals an injection was made into corresponding areas of both epididymides, the maximal interval between the two injections being $5 \mathrm{~min}$. The size of the droplets depends on the tip diameter of the microcapillary, on the injection pressure and on the speed at which the droplets were removed by fluid flow from the site of the injection. The total volume injected was $0.3-1.0 \mathrm{nl}$. The site of the injection was marked with the oil droplets in the connective tissue surrounding the loop of the epididymal duct. At $2 \mathrm{~h}$ after the injection the animals were killed by decapitation and the testes, epididymides and a short portion of the ductus deferens were removed quickly and dropped in physiological salt solution $(0.138 \mathrm{M}-\mathrm{NaCl} ; \mathrm{pH} 7.0)$ containing $9 \%$ alcohol for 5 min to inactivate the epididymal muscular activity and prevent further transport. Dropping in alcohol did not cause any visible spasm of the tubule. Each epididymis was then uncoiled, using a pair of fine forceps, and the distances of the oil droplets from the site of the injection were measured. Displacements of the droplets caused by dissection were small and remained within the accuracy of the measurements, i.e. $0.5 \mathrm{~mm}$. The results were tested with Mann-Whitney $U$ tests and regression analysis.

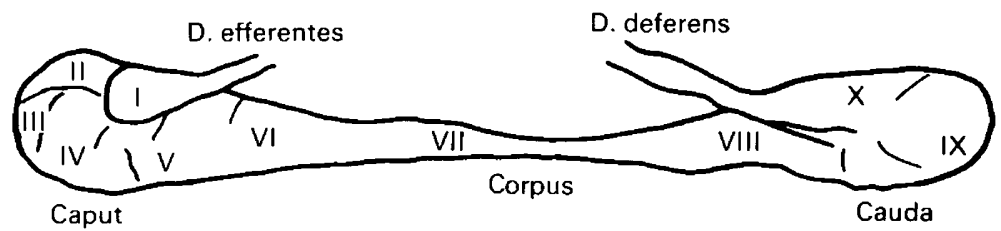

Text-fig. 1. A schematic illustration of the rat epididymis indicating the 10 regions of injection. I, the thicker-walled initial segment; II, III, the thin-walled initial segment; IV, V, VI, the major portions of the caput epididymidis; VII, the corpus epididymidis; VIII, the proximal cauda; IX, the caudal flexure; and X, the distal cauda epididymidis.

\section{Results}

The injected oil droplets did not move all together in the epididymal lumen but became dispersed during the $2 \mathrm{~h}$ period. There was a large variation in the dispersion distances between the animals (Text-fig. 2a), e.g. in region I the greatest dispersion was $542 \mathrm{~mm}$ and shortest $5 \mathrm{~mm}$. The dispersions were not identical in both epididymides of the same animal (see Text-fig. 2a in regions $\mathrm{V}-\mathrm{X}$ ). The dispersions were maximal in the proximal caput in region $\mathrm{I}$ (mean \pm s.e.m. $195 \cdot 3 \pm 64 \cdot 1 \mathrm{~mm})$ and in region III $(72 \cdot 7 \pm 18 \cdot 3 \mathrm{~mm})$ and shortest in the corpus $(15 \cdot 3 \pm 4.7 \mathrm{~mm})$. In region II the mean extent of the dispersion, $42.4 \pm 28.9 \mathrm{~mm}$, was similar to that of region IV $(41.3 \pm 28.9 \mathrm{~mm})$. In the distal caput the dispersions decreased from region IV to $25.6 \pm 7.5 \mathrm{~mm}$ in region VI and in the cauda from $38.8 \pm 7.4$ in region VIII to $20.0 \pm 6.5 \mathrm{~mm}$ in region $\mathrm{X}$. The number of oil droplets injected could not be kept constant but there was no correlation between the extent of dispersion and the number of injected oil droplets. The dispersions of the oil droplets were not distributed normally; the droplets were transported to different distances in groups of different numbers.

The distributions of the distances the oil droplets travelled in each region are shown in Text-fig. 2(b). In the proximal caput, regions I-III, the distributions were discontinuous and obviously multimodal. In the distal caput, regions IV-VI, the modal class was $60 \cdot 0-69 \cdot 0 \mathrm{~mm}$. From the corpus, region VII, to the most distal cauda the distributions appeared bimodal rather than multimodal. In regions IX and $X$ the peaks of the bimodal distributions were in the same classes but the highest peak was in the class of $40 \cdot 0-49 \cdot 9 \mathrm{~mm}$ in region IX and $10 \cdot 0-19.9 \mathrm{~mm}$ in region $X$. In all 
(a)

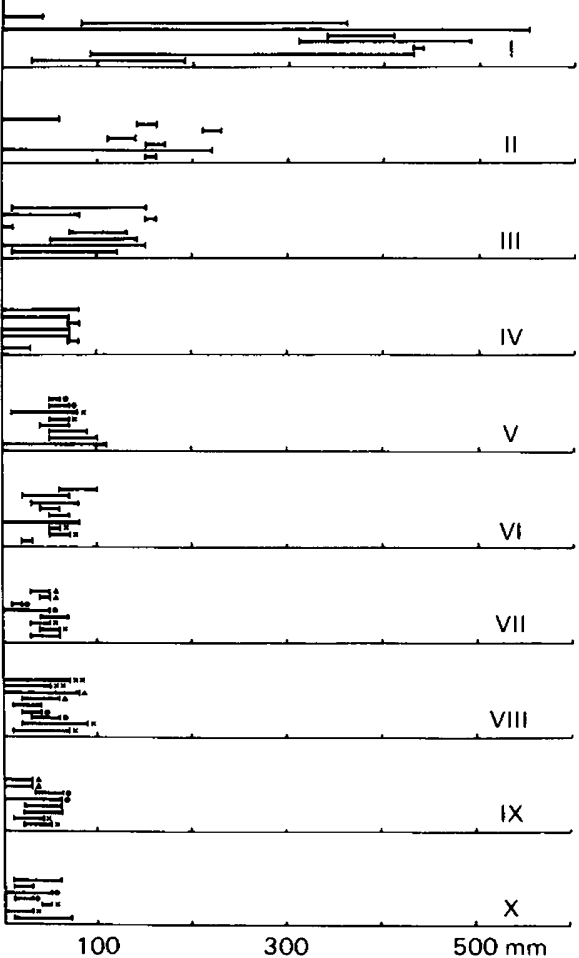

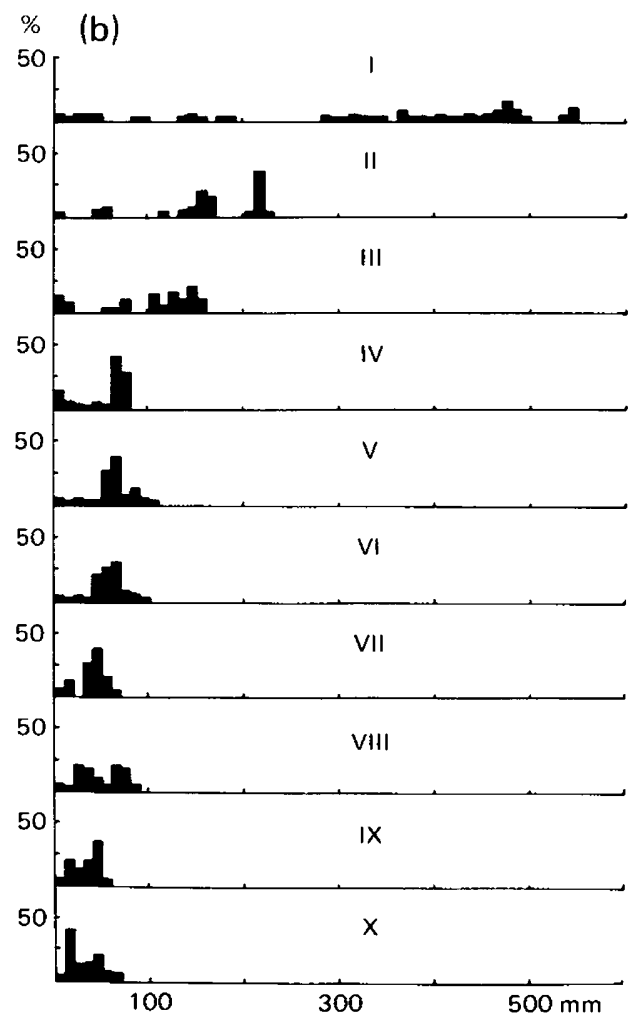

Text-fig. 2. The dispersion distances of the oil droplets from the site of injection (a) and the relative distributions of the transport distances of oil droplets (b) in 10 regions of the epididymis. In (a) the dispersions in the same region of both epididymides of a rat are marked in pairs with the same symbols.

regions of the epididymis there were cases when some oil droplets were found near the injection site after $2 \mathrm{~h}$. In one case, in region III, all the oil droplets were less than $10 \mathrm{~mm}$ from the site of the injection.

The transport distance of the epididymal contents was very great in region I (median $420 \mathrm{~mm}$ ). The total length of this region is about $220 \mathrm{~mm}$ and in most cases the oil droplets were transported through this region during the $2 \mathrm{~h}$ and were found in the neighbouring, narrowest portion of the caput, in regions II or III. The droplets injected in region II were transported for shorter distances than those in region I and had a median of $160.7 \mathrm{~mm}(\mathrm{z}=7.449, P<0.001)$. The transport distance decreased in region III (median $123.6 \mathrm{~mm}, \mathrm{z}=8.013, P<0.001$ ) and again in region IV $(\mathrm{z}=7.545, P<0.001)$ in comparison to the previous region. The regions $\mathrm{IV}, \mathrm{V}$ and $\mathrm{VI}$ have widest outer diameter of the caput tubule. The transport distance of the luminal contents did not differ in these regions, the medians being $64.2,61.8$ and $58.5 \mathrm{~mm}$ respectively. The oil droplets injected into the middle corpus were transported shorter distances than were those injected into the caput (median $41.6 \mathrm{~mm}, z=9.829, P<0.001$ ). In the proximal cauda there was little increase in transport of the oil droplets in comparison to the corpus (median $45.7 \mathrm{~mm}, \mathrm{z}=3.080, P<0.01$ ). In region IX there was a decrease in distance covered in comparison to the proximal cauda (median $36 \mathrm{~mm}, \mathrm{z}=5.334, P<0.001$ ). In region $\mathrm{X}$ the median distance was $25.5 \mathrm{~mm}$.

The greatest decrease of the transport speed was in the proximal caput which consists of about one third of the epididymal length in the rat (Text-fig. 3). If the transport speed is assumed to be constant within each of the 10 segments of the epididymis the transit time would be about $6.7 \mathrm{~h}$ 


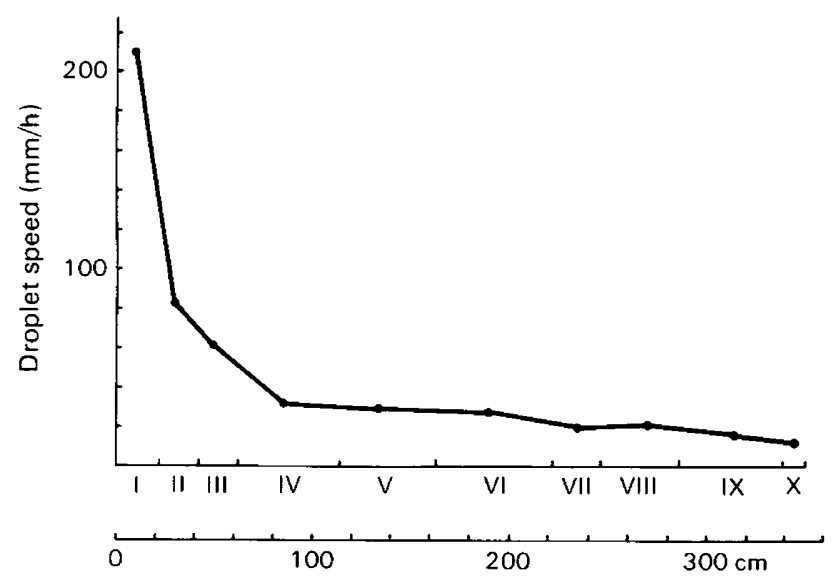

Text-fig. 3. The medians of the transport speeds of the oil droplets in 10 regions of the epididymis. Approximations of the total length of the epididymis and each segment are shown.

through the proximal caput, about 2.9 days through the caput and corpus and about $5 \cdot 3$ days through the whole epididymis when calculated from the medians of the distributions and if regional lengths of the epididymides are the same as measured earlier by Talo et al. (1979).

\section{Discussion}

The oil droplets injected into the lumen of the epididymis moved freely with the epididymal contents and therefore probably indicate accurately the bulk movements of the spermatozoa. It was easy to find the intensely stained oil droplets in the lumen of the epididymis when the duct was uncoiled. The present study is the first quantitative measurement of the transport distances of the epididymal contents. The earlier data for the duration of epididymal transport are based on calculations of the size of the sperm reserves in different parts of the epididymis (Ortavant, 1959; Amann, Johnson, Thompson \& Pickett, 1976) or on the measurement of the duration of transport through the major segments of the epididymis of germ cells labelled with radioactive precursors (Ortavant, 1954; Clermont, Leblond \& Messier, 1959; Monesi, 1962; Amann, Koefoed-Johnsen \& Levi, 1965; Kopecny, 1970; Loir, 1972; English \& Dym, 1982).

There was a large dispersion of the oil droplets, especially in the caput, indicating the stochastic nature of the epididymal transport (Jaakkola \& Talo, 1982, 1983). Activity of the muscle contractions propagating over shorter distances and in both directions in the caput (Talo et al., 1979) may effectively disperse the injected oil droplets, resulting in the large dispersions in the proximal caput. The discontinuous and multimodal distributions of the transport distances in regions I-III may result from the periods of slow and fast transport occurring in both directions in these regions in vitro (Jaakkola \& Talo, 1983).

The transport speed decreased dramatically in the distal caput in the region where the concentration of carnitine in the epididymal lumen increases (Hinton, Snoswell \& Setchell, 1979) and the motility of epididymal spermatozoa begins to increase (Hinton, Dott \& Setchell, 1979). The transport speed remained almost constant in the rest of the caput, corpus and cauda although it slightly decreased towards the ductus deferens. The maturation of spermatozoa increases in that direction (Orgebin-Crist et al., 1975) in parallel with changes in macromolecular and ionic composition of the epididymal lumen (Bedford, 1966; Orgebin-Crist, 1967).

The results of this study show that the contents of the most distal part of the epididymal duct are transported steadily forwards, indicating that the cauda is not a static but rather a dynamic storage 
area. In the rat, the distal portion of the ductus deferens has been suggested to be the last reservoir for the spermatozoa before emission (Hib, Ponzio \& Vilar, 1982). No muscular mechanism acting as a sphincter has been found at the vas-epididymal junction (Baumgarten, Holstein \& Rosengren, 1971), and the contents of the proximal and middle portion of the ductus deferens move back into the cauda epididymidis before emission (Hib et al., 1982). The transit time through the caput and corpus epididymidis, 2.9 days, calculated from the quantitative measurements of the transport speeds in the present study, agrees well with earlier results (Robb, Amann \& Killian, 1978; English \& Dym, 1982), but the duration of transport through the cauda, about 2.4 days, is about half of that found by Robb et al. (1978). No conclusion concerning the transit time of spermatozoa through the cauda may be drawn from the transport speed of the epididymal contents in the short period used in this study. Contractions propagate spontaneously in both directions over long distances in the cauda (Talo et al., 1979). Strong contractions propagating from the direction of the distal end of the ductus deferens, found before emission (Vanwelkenhuyzen, 1966), may propagate further in the cauda over long distances, propelling luminal contents backwards in the long portion of the duct. The contents would therefore have to be transported again through the distal portion of the cauda and the time that spermatozoa stay in the cauda may be longer than expected on the basis of shortterm measurements of the transport speeds.

I thank Mrs Sinikka Hillgren for excellent technical assistance and skilful drawings of the figures and Dr Antti Talo for his advice.

\section{References}

Amann, R.P., Koefoed-Johnsen, H.H. \& Levi, H. (1965) Excretion pattern of labelled spermatozoa and the timing of spermatozoa formation and epididymal transit in rabbits injected with thymidine ${ }^{3} \mathrm{H} . J$. Reprod. Fert. 10, 169-184.

Amann, R.P., Johnson, L., Thompson, D.L. \& Pickett, B.W. (1976) Daily spermatozoal production, epididymal spermatozoal reserves and transit time of spermatozoa through the epididymis of the rhesus monkey. Biol. Reprod. 15, 586-592.

Baumgarten, H.G., Holstein, A.F. \& Rosengren, E. (1971) Arrangement, ultrastructure, and adrenergic innervation of smooth musculature of the ductuli efferentes, ductus epididymis and ductus deferens of man. Z. Zellforsch. mikrosk. Anat. 120, 37-79.

Bedford, J.M. (1966) Development of the fertilizing ability of spermatozoa in the epididymis of the rabbit. J. exp. Zool. 163, 319-329.

Clermont, Y., Leblond, C.P. \& Messier, B. (1959) Duree du cycle de l'épithéilium séminal du rat. Archs Anat. microsc. Morph. exp. 48b, 37-56.

Courot, M. (1981) Transport and maturation of spermatozoa in the epididymis of mammals. Prog. Reprod. Biol. 8, 67-79.

Crabo, B. (1965) Studies on the composition of epididymal content in bull and boars. Acta vet. scand. 6, Suppl. 5.

Crabo, B.G. \& Hunter, A.G. (1975) Sperm maturation and epididymal function. In Control of Male Fertility, pp. 2-23. Eds J. J. Sciarra, C. Markland \& J. J. Speidel. Harper and Row, Hagerstown.

English, H.F. \& Dym, M. (1982) The time required for materials injected into the rete testis to reach points in the caput epididymis of the rat and observations on the absorption of cationic ferritin. Ann. N.Y. Acad. Sci. 383, 445-446.
Hib, J., Ponzio, R. \& Vilar, O. (1982) Contractility of the rat cauda epididymidis and vas deferens during seminal emission. J. Reprod. Fert. 66, 47-50.

Hinton, B.T. \& Setchell, B.P. (1978) Fluid movement in the seminiferous tubules and the epididymal duct of the rat. J. Physiol., Lond. 248, 16P-17P.

Hinton, B.T., Dott, H.M. \& Setchell, B.P. (1979) Measurement of the motility of rat spermatozoa collected by micropuncture from the testis and from different regions along the epididymis. J. Reprod. Fert. 55, 167-172.

Hinton, B.T., Snoswell, A.M. \& Setchell, B.P. (1979) The concentration of carnitine in the luminal fluid of the testis and epididymis of the rat and some other mammals. J. Reprod. Fert. 56, 105-111.

Jaakkola, U.-M. \& Talo, A. (1982) Relation of electrical activity to luminal transport in the cauda epididymidis of the rat in vitro. J. Reprod. Fert. 64, 121126.

Jaakkola, U.-M. \& Talo, A. (1983) Movements of the luminal contents in two different regions of the caput epididymidis of the rat in vitro. J. Physiol., Lond. (in press).

Kopecny, V. (1970) Labelling of mouse spermatozoa with L-arginine ${ }^{14} \mathrm{C}$ (U) monohydrochloride. Z. Zellforsch. mikrosk. Anat. 109, 414-419.

Loir, M. (1972) Métabolisme de l'acide ribonucléique et des protéines dans les spermatocytes et les spermatides de bélier (Ovis aries). II. Variations de l'incorporation et devenir de la ${ }^{3} \mathrm{H}$-lysine, de la ${ }^{3} \mathrm{H}$-arginine et de la ${ }^{35}$ S-cystine. Annls Biol. anim. Biochim. Biophys. 12, 411-429.

Monesi, V. (1962) Autoradiographic study of DNA synthesis and the cell cycle in spermatogonia and spermatocytes of mouse testis using tritiated thymidine. J. Cell Biol. 14, 1-18. 
Orgebin-Crist, M.-C. (1967) Sperm maturation in rabbit epididymis. Nature, Lond. 216, 816-818.

Orgebin-Crist, M.-C., Danzo, B.J. \& Davies, J. (1975) Endocrine control of the development and maintenance of sperm fertilizing ability in the epididymis. In Handbook of Physiology, Sect. 7, Vol. V, Male Reproductive System, pp. 319-338. Eds D. W. Hamilton \& R. O. Greep. American Physiological Society, Washington, D.C.

Ortavant, R. (1954) Détermination de la vitesse de transfert des spermatozoides dans l'épididyme de bélier à l'aide de ${ }^{32}$ P. C. r. Séanc. Soc. Biol. 148, 866868 .
Ortavant, R. (1959) Le cycle spermatogénétique chez le bélier. Annls Zootech. 8, 183-244, 271-322.

Robb, G.W., Amann, R.P. \& Killian, G.J. (1978) Daily sperm production and epididymal sperm reserves of pubertal and adult rats. J. Reprod. Fert. 54, 103-107.

Setchell, B.P. (1978) The Mammalian Testis. Elek, London.

Talo, A., Jaakkola, U.-M. \& Markkula-Viitanen, M. (1979) Spontaneous electrical activity of the rat epididymis in vitro. J. Reprod. Fert. 57, 423-429.

Vanwelkenhuyzen, P. (1966) La motilité du canal déférent. Acta Urol. Belg. 34, 385-466.

Received 22 December 1982 